\title{
Biological and clinical significance of flap endonuclease-1 in triple-negative breast cancer: Support of metastasis and a poor prognosis
}

\author{
LU XU ${ }^{1,2}$, JING-LEI QU ${ }^{1,2}$, NA SONG ${ }^{1,2}$, LING-YUN ZHANG ${ }^{1,2}$, XUE ZENG $^{1,2}$, XIAO-FANG CHE ${ }^{1,2}$, \\ KE-ZUO HOU ${ }^{1,2}$, SHA SHI ${ }^{1,2}$, ZU-YING FENG ${ }^{3}$, XIU-JUAN QU ${ }^{1,2}$, YUN-PENG LIU ${ }^{1,2^{*}}$ and YUE-E TENG ${ }^{1,2^{*}}$ \\ ${ }^{1}$ Department of Medical Oncology, The First Hospital of China Medical University; ${ }^{2}$ Key Laboratory of Anticancer Drugs \\ and Biotherapy of Liaoning Province, The First Hospital of China Medical University, Shenyang, Liaoning 110001, \\ P.R. China; ${ }^{3}$ Boz Life Science Research and Teaching Institute, San Diego, CA 92109, USA
}

Received March 19, 2020; Accepted July 27, 2020

DOI: $10.3892 /$ or.2020.7812

\begin{abstract}
Flap endonuclease-1 (FEN1), a structure-specific nuclease participating in DNA replication and repair processes, has been confirmed to promote the proliferation and drug resistance of tumor cells. However, the biological functions of FEN1 in cancer cell migration and invasion have not been defined. In the present study, using online database analysis and immunohistochemistry of the specimens, it was found that FEN1 expression was associated with a highly invasive triple-negative breast cancer (TNBC) subtype in both breast cancer samples from the Oncomine database and from patients recruited into the study. Furthermore, FEN1 was an important biomarker of lymph node metastasis and poor prognosis in patients with TNBC. FEN1 promoted migration of TNBC cell lines and FEN1 knockdown reduced the number of spontaneous lung metastasis in vivo. Ingenuity Pathway Analysis of FEN1-related transcripts in 198 patients with TNBC demonstrated that the polo-like kinase family may be the downstream target of FEN1. PLK4 was further identified as a critical target of FEN1 mediating TNBC cell migration, by regulating actin cytoskeleton rearrangement. The results of the
\end{abstract}

Correspondence to: Professor Yue-E Teng or Professor Yun-Peng Liu, Department of Medical Oncology, The First Hospital of China Medical University, No. 155 North Nanjing Street, Heping District, Shenyang, Liaoning 110001, P.R. China

E-mail: yeteng@cmu.edu.cn

E-mail: ypliu@cmu.edu.cn

"Contributed equally

Abbreviations: FEN1, flap endonuclease-1; PLK4, polo-like kinase 4; TNBC, triple-negative breast cancer; ER, estrogen receptor; PR, progesterone receptor; Her-2, human epidermal growth factor receptor-2; RFS, relapse-free survival; DMFS, distant metastasis-free survival; OS, overall survival

Key words: FEN1, triple negative breast cancer, prognosis, metastasis, PLK4 present study validate FEN1 as a therapeutic target in patients with TNBC and revealed a new role for FEN1 in regulating TNBC invasion and metastasis.

\section{Introduction}

Triple-negative breast cancer (TNBC) is defined as breast cancer that lacks expression of the estrogen receptor (ER), progesterone receptor (PR), and human epidermal growth factor receptor 2 (HER2). TNBC is poorly differentiated and there is an increased risk to develop visceral metastases early during the development of cancer, which eventually leads to worse prognosis and poor survival rates (1-3). Therefore, metastasis is the key challenge to overcome in patients with TNBC. Recent findings demonstrated that genomic instability is a driver of metastasis, particularly in TNBC $(4,5)$. Genomic instability was also found in a pan-cancer genomic analysis of metastatic tumors (6). Thus, it is imperative to identify novel and targetable molecules, that regulate the progression of aggressive breast cancers.

DNA replication and repair are vital mechanisms in the maintenance of genomic stability and alterations in these processes can promote the evolution of cancer cells via the accumulation of gene copy number changes, rearrangements, and mutations (7). Flap endonuclease-1 (FEN1) plays critical roles in both DNA replication and repair, by participating in the maturation of the Okazaki fragment, rescuing stalled replication forks, maintaining telomere stability and DNA long-patch base excision repair (8-10). An increasing amount of evidence shows that the overexpression of FEN1 in several types of tumor affects the proliferation, apoptosis, and drug resistance of tumor cells, which was also associated with poor prognosis (9,11-24). In addition, previous research showed that FEN1 mediated microRNA-200a methylation to promote breast cancer cell growth via the MET and EGFR signaling pathway (24). However, the function and molecular mechanisms of FEN1 in metastasis, particularly in highly invasive TNBC, has not been investigated. Due to the important roles of FEN1 in DNA metabolic processes, the effects of FEN1 on breast cancer invasion and metastasis were investigated. 
In the present study, a high expression of FEN1 was found in the ER-negative/TNBC subtype, and was an important biomarker of lymph node metastasis and poor prognosis in patients with TNBC using the online database and immunohistochemistry (IHC) analysis from patients recruited into the study. In addition, FEN1 was found to promote TNBC cell migration in vitro and the formation of lung metastasis in vivo, which was associated with cytoskeletal reorganization by modulating the expression of PLK4. These results indicated that FEN1 was an important regulator of TNBC migration and a potential target for TNBC treatment.

\section{Materials and methods}

Analysis of FEN1 in COSMIC database and Oncomine database. The Catalogue of Somatic Mutations in Cancer (COSMIC) database is a high-resolution database system that collects somatic mutation data in the genetics of human cancer (http://cancer.sanger.ac.uk) (25). The latest release (COSMIC v81) was employed to examine the variant status of FEN1 in human cancer. The study presents the data and analytical results for point mutations, copy number variation and changes of gene expression from 3,281 tumors among 12 tumor types.

The expression levels of FEN1 in breast cancers were analyzed in Oncomine gene expression array datasets (www. oncomine.org) (26). We searched FEN1 in the database, using thresholds of $\mathrm{P}<0.05$ and fold change $>1.5$. The t-test was conducted both as one-sided for overexpression analysis and two-sided for differential expression analysis.

Patient tissue specimens and immunohistochemistry (IHC). The tissue microarray (TMA) was constructed in collaboration with Shanghai Biochip as described in our previous study (27). The inclusion criteria were invasive breast cancer, and clinical data and follow-up data were complete. The exclusion criteria were preoperative therapy, pathological type of breast carcinoma in situ, simultaneous bilateral breast cancer, double cancer, and RFS time $<6$ months, with a final enrollment of 248 patients. Expression of ER, PR and HER 2 was assessed according to the American Society of Clinical Oncology/College of American Pathologists (ASCO/CAP) guidelines. The follow-up date was followed from the patient's surgery day, every 6 months. The current study includes follow-up data available as of October 31, 2018. Tumors were staged according to the criteria set by the American Joint Committee on Cancer (AJCC) (7th edition). The relapse-free survival (RFS) was set in the period from the date of surgery to recurrence. The distant metastasis-free survival (DMFS) was set for the period from the date of surgery to distant metastasis. Overall survival (OS) was set in the period from the date of surgery to death or to the most recent clinic visit.

The primary antibody used for IHC included mouse anti-human FEN1 (working concentrations were 1:200), purchased from Santa Cruz Biotechnology. The results of IHC were assessed with double-blind method, the staining results were reviewed and approved by two specialists in Department of Pathology in the First Hospital of CMU. The positive staining of FEN1 was cytoplasmic or nuclear patches of brown scored (21). The scale quantified the extent of expression: 0 , no detectable or only trace staining; 1 , weak expression; 2 , strong expression. Score 0 was considered as 'low expression', and score 1 and 2 were considered 'high expression'. This study was approved by the Ethics Committee of the First Hospital of China Medical University, and written informed consent was obtained from each patient. Animal experiments were approved by the China Medical University Application for Laboratory Animal Welfare and Ethical review.

Cell culture and lentiviral transfection. The human triple-negative breast cancer cell lines MDA-MB-231 and HCC1937 were obtained from the Type Culture Collection of the Chinese Academy of Sciences. MDA-MB-231 was cultured in L-15 (Gibco; Thermo Fisher Scientific, Inc.) and HCC1937 was cultured in RPMI-1640 (Gibco; Thermo Fisher Scientific, Inc.) supplemented with $0.11 \mathrm{~g} / 1$ sodium pyruvate, $2.5 \mathrm{~g} / 1$ glucose, $1.5 \mathrm{~g} / 1$ sodium bicarbonate. The cells were cultured containing $10 \%$ heat-inactivated fetal bovine serum (Gibco; Thermo Fisher Scientific, Inc.), $100 \mathrm{U} / \mathrm{ml}$ penicillin and $100 \mu \mathrm{g} / \mathrm{ml}$ streptomycin in a humidified incubator at $37^{\circ} \mathrm{C}$ with an atmosphere of $5 \% \mathrm{CO}_{2}$. Mycoplasma testing was carried out for the two cell lines.

Virus production and FEN1-related infection were performed as described previously (24). In brief, the lentiviral vectors LV-GFP-FEN1-RNAi, LV-GFP-FEN1-3FLAG and empty vector controls were synthesized (Genechem Company). Target sequences of FEN1 were 5'-GGGTCAAGAGGCTGA GTAA-3' (sense), 5'-UUACUCAGCCUCUUGACCCdTdT-3' (anti-sense), negative control: 5'-UUCUCCGAACGUGUC ACGUtt-3' (sense), 5'-ACGUGACACGUUCGGAGAAtt-3' (anti-sense). The breast cancer cells in logarithmic phase of growth were infected with lentivirus according to the multiplicity of infection (MOI) with density $1 \times 10^{5}$ cells/well. The medium for the transfected cells was supplemented with polybrene $(5 \mu \mathrm{g} / \mathrm{ml})$ and Enhanced Infection Solution (Genechem Company) to elevate the transfection efficiency. Polybrene and virus for silencing or overexpressing FEN1 were added to infect MDA-MB-231 (MOI=40) and HCC-1937 (MOI=60). After 120-h infection, GFP expression was detected by florescent microscopy (BX61, Olympus). Western blot analysis was performed to detect the knockdown and overexpressing efficiency.

Transwell migration assay and xenograft studies. A 24-well chemotaxis chamber $(8-\mu \mathrm{m}$ pore size; Corning) was used in this experiment. Briefly, $2 \times 10^{4}$ cells of MDA-MB-231 and $4 \times 10^{4}$ cells of HCC-1937 were loaded onto the upper well of the Transwell chamber with serum-free culture medium, while the medium containing 2.5\% FBS for MDA-MB-231 and $10 \%$ FBS for HCC-1937 as an attractant added to the bottom chamber. After incubating plates for $24 \mathrm{~h}$ at $37^{\circ} \mathrm{C}$, migration was assessed using the trypan-blue dye method.

Athymic nude (nu/nu) mice, female, 4-6 weeks of age, were purchased from Vital River and housed in a sterile room at the Experimental Animal Center of CMU University at $25^{\circ} \mathrm{C}$ and $40-70 \%$ humidity, with a 12-h light/dark cycle and free access to food and water. Lentivirus-transfected MDA-MB-231 cells were harvested. The concentration of cell suspensions was adjusted to $2 \times 10^{6}$ cells $/ 100 \mu \mathrm{l}$ with PBS, and then injected into the caudal vein of nude mice. At least 5 mice 
were used for each group. Mice were monitored for symptoms related to tumor growth including an arched back, unsteady gait, and paralysis of legs and body weight loss each week. Eight weeks later, no mice died. The method of euthanasia was cervical dislocation (when the heart stopped completely, the mouse was determined as dead) after a total body weight loss of $20 \%$ or severe symptoms were observed. Lung tissues were fixed in $4 \%$ paraformaldehyde for later staining of pathological tissue sections. Hematoxylin and eosin (H\&E) staining was used for verifying cancer tissues and confirming the pulmonary metastatic lesions under a microscope. IHC staining was used for checking the expression of FEN1. Anti-human FEN1 (working concentrations were 1:150) were purchased from ZSGB-Bio (TA802762). The mice were housed and maintained under standard NIH protocol.

RNA-seq and RNA-Seq data analysis. RNA-sequencing (RNA-seq) technology was utilized to investigate changes in cell mRNA profiles with FEN1 siRNA vs. the control group in MDA-MB-231 cells. After total RNA was extracted, mRNA was isolated according to the manufacturer's instructions. RNA integrity was assessed using the RNA Nano 6000 assay kit of the Bioanalyzer 2100 system (Agilent Technologies). Libraries were generated using the NEBNext ${ }^{\circledR}$ Ultra $^{\mathrm{TM}}$ Directional RNA Library Prep kit for Illumina ${ }^{\circledR}$ (NEB). The libraries were sequenced on an Illumina Hiseq 4000 platform and $150 \mathrm{bp}$ paired end reads were generated. The differential expression genes were evaluated using Ballgown. Transcripts with a q-value $<0.01$ and $\mid \log _{2}$ (fold change) $\mid>1$ were assigned as DEGs. Based on the DEGs, R/fGSEA package was used (biorxiv, doi: https://doi.org/10.1101/060012) with MSigDB for pathways analysis.

Ingenuity pathway analysis of GSE76124 and correlation analysis of FEN1 and PLK4. Raw data from publicly available datasets focusing on the largest dataset of TNBC patients were downloaded from Gene Expression Omnibus (GEO): Accession number GSE76124. To explore possible molecular functions and biological networks of FEN1, the samples in GSE76124 were divided into two groups according to high (top 25\%) and low (bottom 25\%) FEN1 expression. A total of 699 genes which had a log-fold change $\geq 1$ and a P-value $<0.05$ were considered to be significantly differentially expressed and were imported into Ingenuity Pathway Analysis (IPA, http://www.ingenuity.com) (28). The most affected biological functions included promoting tumorigenesis, migration and cell movement and inhibiting cell apoptosis, necrosis, and cell death. Additionally, the correlation between FEN1 and PLK4 expression was analyzed through Spearman's correlation analysis. Additionally, PPI analysis was conducted to reveal the molecular mechanisms between FEN1 and PLK4. The STRING protein database 11.0 (http://string-db.org/) was utilized to construct the PPI networks.

Western blot analysis and co-immunoprecipitation. For western blot analysis, the process was described previously (29). The membrane was incubated with the indicated primary and secondary antibodies, and the proteins were visualized by an enhanced ECL kit (Beyotime). Imaging Densitometer with Molecular Analyst Software (Bio-Rad) was used to compare the gel images and expressed as the ratios to the density of GAPDH bands.

Immunoprecipitations were performed as described previously (29). Ethidium bromide was added to a final concentration of $60 \mathrm{mg} / \mathrm{ml}$ to disrupt DNA protein interactions in endogenous protein co-IP experiments. Cell lysis was centrifuged for $5 \mathrm{~min}$ at $1,000 \mathrm{x} \mathrm{g}$ at $4^{\circ} \mathrm{C}$ and the supernatant (5-10 $\mathrm{mg}$ ) was incubated with the indicated primary antibodies (5-10 $\mu \mathrm{g}$ ) and protein-A beads (Invitrogen; Thermo Fisher Scientific, Inc.) at $4^{\circ} \mathrm{C}$ overnight. The beads were washed three times with cell lysis buffer and the precipitated proteins were subjected to western blot analysis. The primary and secondary antibodies are listed in Table SI.

Immunofluorescence staining. Cells were transfected for $72 \mathrm{~h}$ and fixed with ice-cold methanol and permeabilized with $0.2 \%$ Triton X-100. Actin filaments were stained with Rhodamine Phalloidin [Thermo Fisher Scientific, Inc.; R415)] linked to Texas Red (red staining), and the nuclei were counterstained with DAPI (blue staining). The data are presented as mean \pm SD of the membrane/cytosol actin fluorescent intensity ratio relative to the control $(n=3)$. Images were captured via a confocal laser scanning microscope with x400 magnification. Each experiment was performed in triplicate. The red values of the 40 cells per condition were quantified using Image J software by measuring $10 \mu \mathrm{M}$ distances encompassing the extracellular area, the full thickness of the membrane and the intracellular space. Each experiment was repeated three times.

Statistical analysis. Each experiment was repeated at least 3 times unless otherwise specified. Group data comparisons were conducted by t-test. The results were expressed as mean \pm standard deviation (SD) in this study. Categorical parameters were compared using the $\chi^{2}$ test or Fisher's exact test. Kaplan-Meier analysis and a log-rank test were used to determine survival. Correlation analysis was determined using Pearson's correlation. Statistical differences between groups were considered significant if $\mathrm{P}<0.05$. Data were analyzed by SPSS statistical software (version 18.0).

\section{Results}

FEN1 variants in different types of human cancer, and the association between FEN1 mRNA expression levels and the clinical characteristics in patients with breast cancer. The different types of cancer with complete information on point mutations, copy number variations, and the mRNA expression level of the FEN1 gene are shown in Fig. 1 . The $0.11 \%$ patients with breast cancer $(3 / 2,620$ cases) exhibited FEN1 gene point mutations, $0.45 \%$ (7/1,544 cases) exhibited FEN1 gene copy number gains, and 7.07\% (78/1,104 cases) exhibited FEN1. The results show that the frequency of point mutations, change in copy number and copy number variation frequency was low $(<0.5 \%$ in breast cancer). There was also a marked increase in the gene expression level of FEN1 in patients with breast cancer (7.07\% among 1,104 patients), indicating overexpression of FEN1 was more common in patients with breast cancer.

Subsequently, the FEN1 mRNA expression level between normal and cancer tissue was analyzed in data obtained from the Oncomine database. The results showed that FEN1 was 


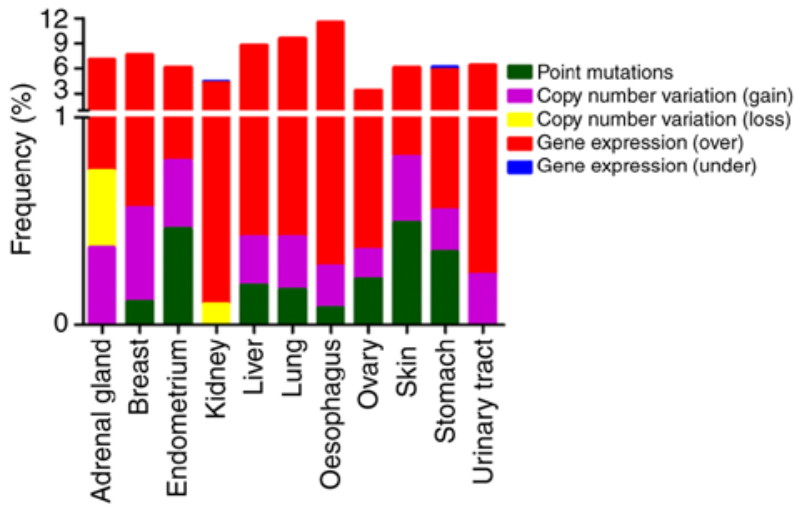

Figure 1. Data from the COSMIC database revealed the frequency of point mutations, copy number variants, and gene expression variants for human FEN1 in different types of cancer. The results revealed that $0.11 \%$ patients with breast cancer $(3 / 2,620$ cases) exhibited FEN1 gene point mutations, $0.45 \%$ (7/1,544 cases) exhibited FEN1 gene copy number gains, and $7.07 \%$ (78/1,104 cases) exhibited FEN1 mRNA upregulation. FEN1, flap endonuclease-1.

expressed at high levels, in almost all types of solid tumor (Fig. 2A). In addition, FEN1 expression was increased in the ER/PR-negative and TNBC subtypes (Fig. 2B). Furthermore, FEN1 expression levels were significantly higher in patients with advanced $\mathrm{N}$ and $\mathrm{M}$ stage across the four analyses $(\mathrm{P}=0.003)$ and with a metastatic event at $1-(\mathrm{P}=5.81 \mathrm{E}-4)$, 3- $(\mathrm{P}=7.09 \mathrm{E}-5)$ and 5-years $(\mathrm{P}=0.007)$ following diagnosis (Fig. 2C). In addition, in a comparison with patients who were still alive, those who had died after 1- and 5-years exhibited FEN1 overexpression ( $\mathrm{P}=9.34 \mathrm{E}-5$ and $\mathrm{P}=0.003$, respectively) (Fig. S1A and B). Using online database analysis, it was found that the high expression level of FEN1 was associated with the TNBC subtype and was significantly associated with the occurrence of breast cancer metastasis and poor prognosis.

Patient characteristics and FEN1 expression. To further confirm the aforementioned results, the prognostic value of FEN1, at the protein level in a tissue microarray (TMA) from 248 human breast cancer samples from patients with breast cancer, recruited into the present study, was investigated. The clinicopathological characteristics are summarized in Table SII. The enrolled patients were 28-62 years of age (median age, 51 years). The median follow-up time was 128.6 months, with 73 patients $(29.4 \%)$ having tumor recurrence, 49 patients $(19.8 \%)$ had a distant metastasis, and 48 patients $(19.4 \%)$ had succumbed to the disease; six patients were lost to follow up and were not included in the survival analysis. FEN1 staining was found to be strong in the cytoplasm surrounding the stromal cells (Fig. 3A). Of the 248 cancer specimens in the current study, $158(63.7 \%)$ demonstrated a high FEN1 expression.

FEN1 protein expression is associated with lymph node metastasis and is a poor prognosis marker in patients with $T N B C$. The association between FEN1 expression level and the clinicopathological characteristics of the cohort is shown in Table I. High expression levels of FEN1 were significantly associated with the TNBC phenotype $(\mathrm{P}=0.036)$
(Fig. 3B, Table I), but not with age $(\mathrm{P}=0.571)$, histological grade $(\mathrm{P}=0.635)$, tumor size $(\mathrm{P}=0.067)$, lymph node positivity $(\mathrm{P}=0.081)$, (Table I). Using Kaplan-Meier analysis of all the patients, high FEN1 expression was not significantly associated with relapse-free survival (RFS) $(\mathrm{P}=0.54)$, distant metastasis-free survival (DMFS) $(\mathrm{P}=0.15)$, or overall survival (OS) $(\mathrm{P}=0.069)$ in 248 breast cancer patients (Fig. 3C).

In a 77 TNBC patients subset $(n=77), 50.2 \%$ of the patients expressed high levels of FEN1, and was associated with lymph node positivity $(\mathrm{P}=0.025)$, but not with age $(\mathrm{P}=0.616)$, histological grade $(\mathrm{P}=0.273)$, tumor size $(\mathrm{P}=0.518)$, or tumor stage $(\mathrm{P}=0.073)$ (Table II). From the Kaplan-Meier analysis of patients with TNBC, high FEN1 expression was associated with worse RFS ( $\mathrm{P}=0.025)$, DMFS $(\mathrm{P}=0.001)$, and $\mathrm{OS}$ $(\mathrm{P}=0.012)$ (Fig. 3D). Taken together, the data revealed that high FEN1 protein expression was also positively associated with the TNBC subtype and could be a biomarker for poor prognosis in patients with TNBC.

FEN1 expression in TNBC is associated with their migratory phenotype both in vitro and in vivo. To investigate the role of FEN1 during TNBC cell migration and metastasis, a Transwell assay was performed using MDA-MB-231 and HCC-1937 cells, which were transfected with FEN1 knockdown and overexpressing lentivirus vectors, respectively. In both cell lines, the efficiency of FEN1 knockdown and overexpression exceeded $80 \%$, as confirmed by fluorescence (Fig. 4A) and western blot analysis (Fig. 4B). The results of the Transwell assay showed that when FEN1 was silenced, the migration abilities of the two cell lines were significantly decreased with $59.4 \pm 5.11 \%$ inhibition in MDA-MB-231 cells $(\mathrm{P}=0.0052)$ and $44.33 \pm 9.97 \%$ inhibition in HCC1937 cells $(\mathrm{P}=0.0105)$ (Fig. 4C and D). The migration abilities of the two cell lines were significantly increased when FEN1 was overexpressed compared with that in the control cells; $227.1 \pm 11.41 \%$ in MDA-MB-231 cells $(\mathrm{P}=0.0027)$ and $306.31 \pm 16.27 \%$ in HCC1937 cells $(\mathrm{P}=0.0021)$ (Fig. 4C and D).

Next, a nude mouse lung metastatic model was created by injecting transfected MDA-MB-231 cells into the tail vein. $H \& E$ staining was performed to determine the degree of metastases, while IHC staining was performed to detect FEN1 expression (Fig. 4E). The carcinogenesis rates in the control and experimental groups were both $100 \%$. The number of metastases in the NC-KD and KD-FEN1 groups were $18.8 \pm 4.9$ and $6 \pm 2.3(\mathrm{P}=0.0014)$. The number of metastases in the NC-OE and OE-FEN1 groups were $31.0 \pm 2.7$ and $67.8 \pm 13.2$ $(\mathrm{P}=0.0004)$ (Fig. 4F). These results suggested direct evidence for the role of FEN1 in promoting TNBC cell metastasis in vitro and in vivo.

FEN1 promotes cell migration and mitosis in TNBC by analyzing RNA-seq profile data from MDA-MB-231 cells and clinical TNBC tissues. The gene expression profiles showed 4,014 DEGs after FEN1 knockdown; 2,328 were upregulated, while 1,686 were downregulated (Fig. 5A). To further verify the functions of the FEN1-related DEGs in TNBC (Table SIII), GSEA was performed and the results revealed that the functions of FEN1 were enriched in mitotic spindle, DNA repair, spermatogenesis, E2F targets and $\mathrm{G}_{2} / \mathrm{M}$ checkpoint (Fig. 5B). 
A

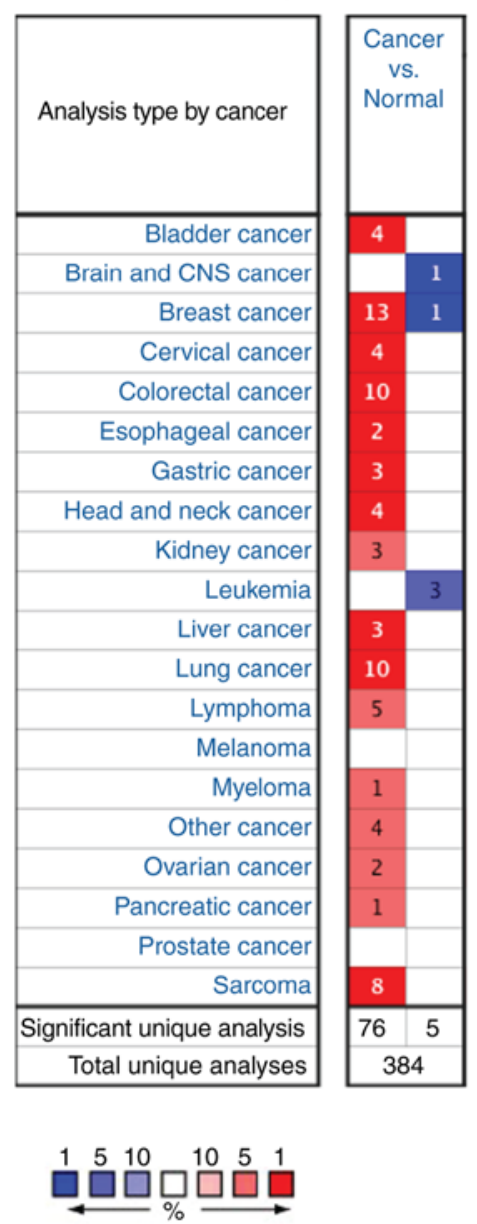

B

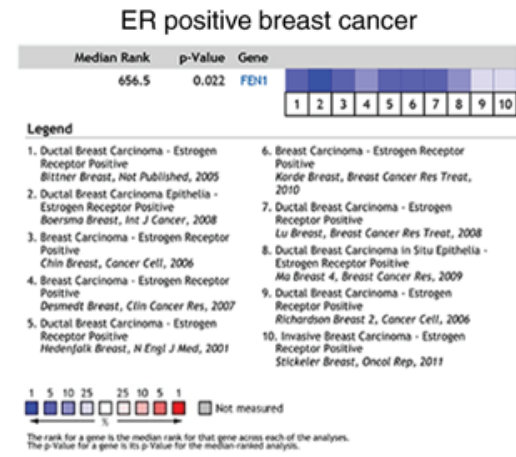

C
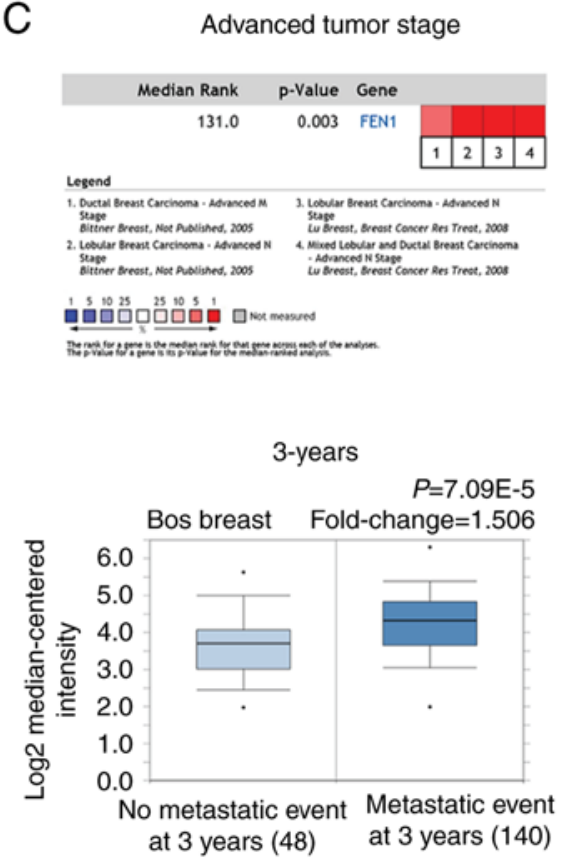

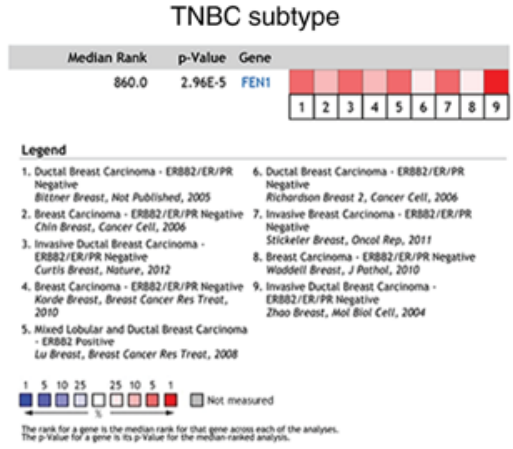

1-year $P=5.81 \mathrm{E}-4$

Schmidt breast Fold-change $=1.869$
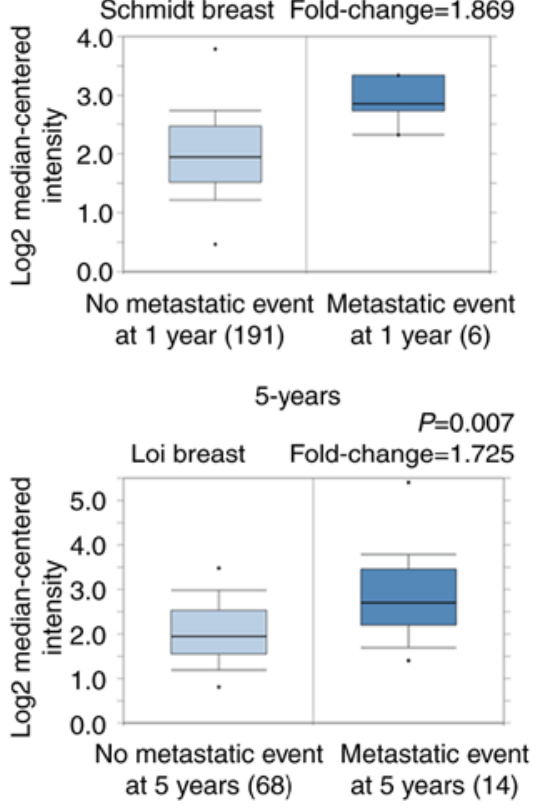

Figure 2. FEN1 mRNA expression level in cancer using the Oncomine database. (A) Summary view for the FEN1 expression levels in different types of cancer compared with that in normal tissues. P $<0.05$ and fold change $>1.5$. (B) Elevated mRNA expression level of FEN1 in ER-positive breast cancer and ERBB2/ER/PR-negative breast cancer. (C) Elevated mRNA expression levels of FEN1 were detected in patients with advanced N or M stage and metastatic event at 1-, 3-, and 5-years following diagnosis. FEN1, flap endonuclease-1; ER, estrogen receptor; PR, progesterone receptor.

Next, the IPA software was used to analyze the 699 FEN1-related DEGs in 198 clinical TNBC tissues from the GSE76124 dataset (Fig. 5C; Table SIV). The results revealed multiple related biological functions and diseases that were significant $(\mathrm{P}<0.05)$, and the top 20 are presented in Fig. 5D. The most affected biological functions in patients with TNBC and high expression levels of FEN1 were involved in promoting tumorigenesis, migration and cell movement, and inhibiting cell apoptosis, necrosis, and cell death. These results suggested that high FEN1 expression plays an important role in the occurrence of malignant tumors by promoting the invasion, metastasis and proliferation of tumors, which was consistent with the aforementioned results.

To further investigate the FEN1-related biological functions, canonical pathways were identified, and the top eight significant pathways are shown in Fig. 5E. The analysis demonstrated that high FEN1 expression was associated with the activation of cell cycle progression (such as estrogen-mediated S-phase entry, $\mathrm{P}=1.86 \times 10^{-10}$, z score, 1.67 ; mitotic roles of polo-like kinase, $\mathrm{P}=1.23 \times 10^{-9}, \mathrm{z}$ score, 2.11 ; and cell cycle control of chromosomal replication, $\mathrm{P}=6.31 \times 10^{-13}$ ), suppression of cell cycle checkpoints (such as the cell cycle: $\mathrm{G}_{2} / \mathrm{M}$ DNA damage checkpoint regulation, $\mathrm{P}=3.31 \times 10^{-9}$, and $\mathrm{z}$ score, -1.51), disruption of the DNA repair pathway (such as role of BRCA1 in DNA damage response, $\mathrm{P}=1.23 \times 10^{-8}$, $\mathrm{z}$ score, 0.63; and mismatched repair, $\left.\mathrm{P}=2.14 \times 10^{-9}\right)$, and another two pathways (hepatic fibrosis/hepatic stellate cell activation, $\mathrm{P}=1.99 \times 10^{-12}$ and agranulocyte adhesion and diapedesis, $\mathrm{P}=1.10 \times 10^{-9}$ ). Therefore, we hypothesized that FEN1 may participate in dysfunction of the mitosis pathway to promote cell migration.

FEN1 promotes the migration and invasion of TNBC cells by modulating the expression level of PLK4. Mitotic roles of polo-like kinase, which was identified as one of the prominent pathways associated with FEN1 high expression, was further investigated and a significant positive correlation between FEN1 and PLK1/PLK4 expression was found among all the 


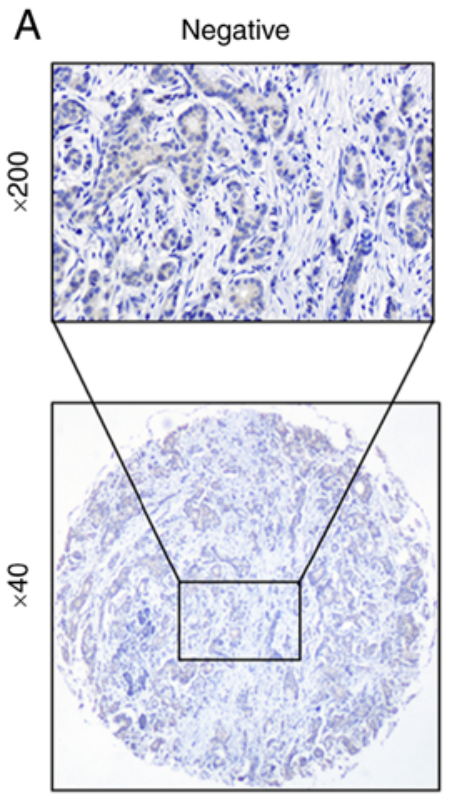

B

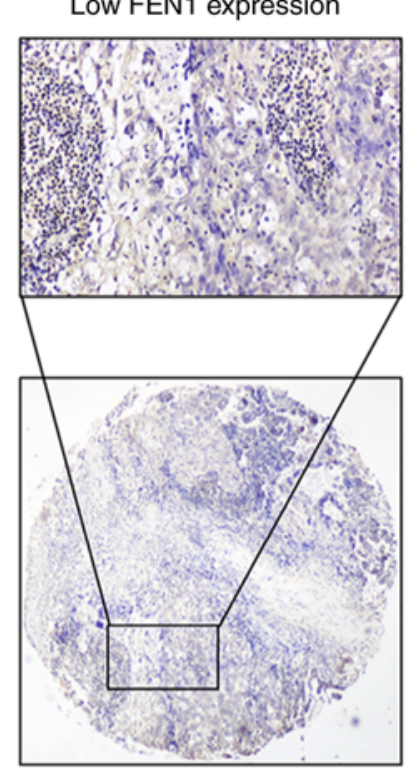

C

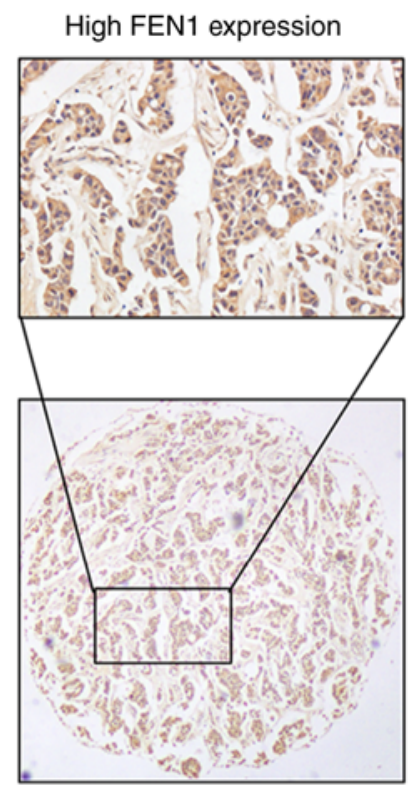

D

All breast cancer patients $(\mathrm{N}=248)$
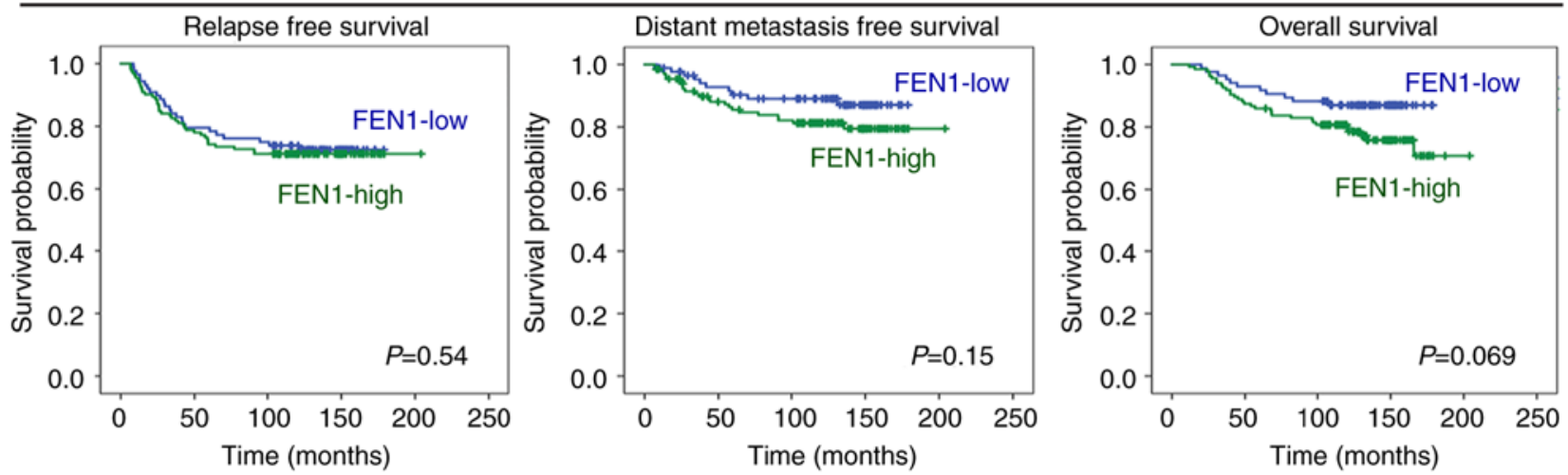

$\mathrm{E}$

Triple negative breast cancer patients $(\mathrm{N}=77)$
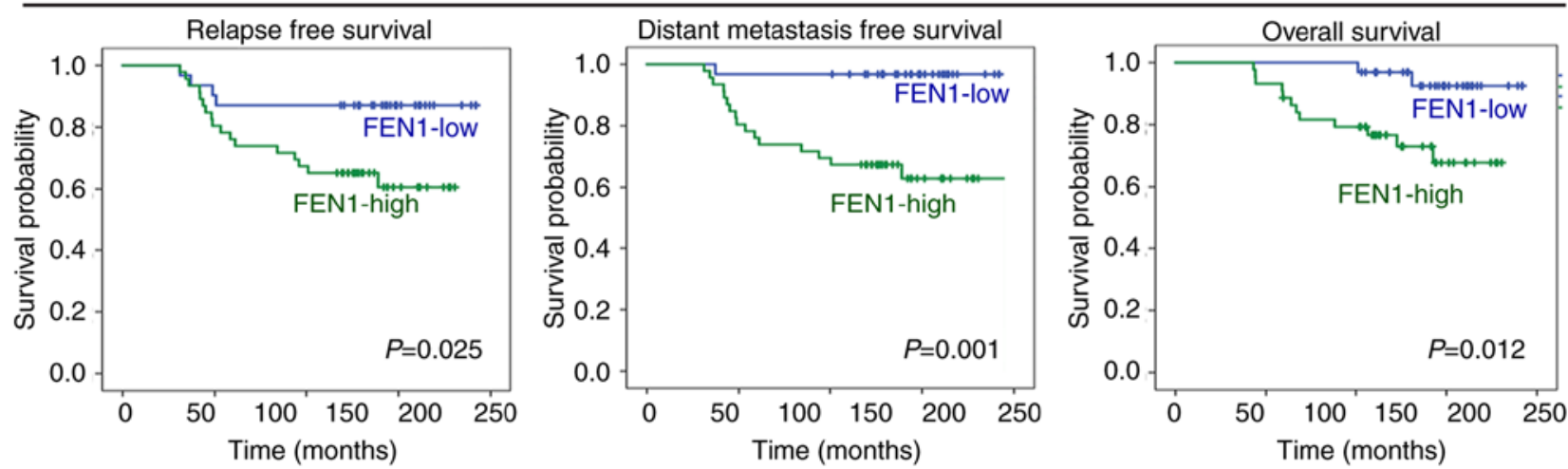

Figure 3. Identification of FEN1 as a poor prognosis marker in patients with TNBC. (A) Representative images of negative, low and high FEN1 staining in breast cancer samples from the tissue microarray. (B) Strong staining was observed both in the cytoplasm and nucleus (brown). (C) High protein expression levels of FEN1 were found in patients with TNBC. (D and E) Kaplan-Meier survival curves based on FEN1 expression for relapse-free survival, distant metastasis-free survival, and overall survival in all patients with breast cancer and with TNBC. FEN1, flap endonuclease-1; TNBC, triple negative breast cancer.

5 members of the PLK protein family, while Pearson's correlation was highest $(\mathrm{r}=0.75 ; \mathrm{P}<0.0001)$ between FEN1 and PLK4 (Fig. 6A).

To investigate the mechanism of FEN1-related increase in migration, the Search Tool for the Retrieval of Interacting Genes/Proteins (STRING) database (https://string-db.org/) was used to predict the interaction of FEN1 with PLK4 (Fig. 6B). Western blot analysis revealed that knockdown of FEN1 attenuated the protein expression level of PLK4 in the MDA-MB-231 cell line, and vice versa (Fig. 6C). However, immunoprecipitation experiments did not reveal a direct interaction between FEN1 and PLK4 (Fig. 6D). Taken together the 
Table I. Relationship between the expression of FEN1 and clinicopathological characteristics in 248 patients with breast cancer.

\begin{tabular}{|c|c|c|c|c|}
\hline \multirow[b]{2}{*}{ Characteristics } & \multirow[b]{2}{*}{ Cases } & \multicolumn{2}{|c|}{ FEN1 expression in $\mathrm{BC}$} & \multirow[b]{2}{*}{ P-value } \\
\hline & & Low $(\%)$ & $\operatorname{High}(\%)$ & \\
\hline Age (year) & & & & 0.571 \\
\hline$<50$ & 107 & $40(37.4)$ & $67(62.6)$ & \\
\hline$\geq 50$ & 141 & $50(35.5)$ & $91(64.5)$ & \\
\hline Histological grade & & & & 0.635 \\
\hline $\mathrm{I}, \mathrm{II}$ & 140 & $81(57.9)$ & $59(42.1)$ & \\
\hline III & 48 & $9(18.8)$ & $39(81.2)$ & \\
\hline Tumor size & & & & 0.067 \\
\hline$\leq 2 \mathrm{~cm}$ & 82 & $28(34.1)$ & $54(65.9)$ & \\
\hline$>2 \mathrm{~cm}$ & 166 & $62(37.3)$ & $104(62.7)$ & \\
\hline $\mathrm{pN}$ stage & & & & 0.081 \\
\hline No & 112 & $53(47.3)$ & $59(52.7)$ & \\
\hline $\mathrm{N} 1+2+3$ & 136 & $37(27.2)$ & $99(72.8)$ & \\
\hline Tumor subtype & & & & $0.036^{\mathrm{a}}$ \\
\hline Non-TNBC & 171 & $67(39.2)$ & $104(60.8)$ & \\
\hline TNBC & 77 & $23(29.9)$ & $54(70.1)$ & \\
\hline
\end{tabular}

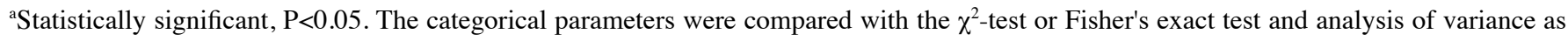
appropriate.

Table II. Relationship between the expression of FEN1 and clinicopathological characteristics in 77 patients with TNBC.

\begin{tabular}{|c|c|c|c|c|}
\hline \multirow[b]{2}{*}{ Characteristics } & \multirow[b]{2}{*}{ Cases } & \multicolumn{2}{|c|}{ FEN1 expression in TNBC } & \multirow[b]{2}{*}{ P-value } \\
\hline & & Low $(\%)$ & High (\%) & \\
\hline Age (year) & & & & 0.616 \\
\hline$<50$ & 40 & $14(35.0)$ & $26(65.0)$ & \\
\hline$\geq 50$ & 37 & $9(24.3)$ & $28(75.7)$ & \\
\hline Histological grade & & & & 0.273 \\
\hline I, II & 45 & $16(35.6)$ & $29(64.4)$ & \\
\hline III & 20 & $7(35.0)$ & $13(65.0)$ & \\
\hline Tumor size & & & & 0.518 \\
\hline$\leq 2 \mathrm{~cm}$ & 25 & $10(40.0)$ & $15(60.0)$ & \\
\hline$>2 \mathrm{~cm}$ & 52 & $13(25.0)$ & $39(75.0)$ & \\
\hline $\mathrm{pN}$ stage & & & & $0.025^{\mathrm{a}}$ \\
\hline No & 25 & $12(48.0)$ & $13(52.0)$ & \\
\hline $\mathrm{N} 1+2+3$ & 52 & $11(21.2)$ & $41(78.8)$ & \\
\hline
\end{tabular}

aStatistically significant, $P<0.05$. Categorical parameters were compared with the $\chi^{2}$-test or Fisher's exact test and analysis of variance as appropriate.

results indicated that the regulation of PLK4 by FEN1 may be at the protein level.

Previous studies have reported that PLK4 promoted the migration and metastasis by epithelial-mesenchymal transition (EMT), MMPs $(30,31)$ and actin cytoskeleton $(32,33)$. The western blot assay revealed that the change in FEN1 expression could not change the protein expression levels of EMT-associated proteins and MMPs in the MDA-MB-231 cell line (Fig. 6E). Subsequently, the effects of FEN1 on modulating cytoskeleton rearrangement were further investigated and F-actin staining, using phalloidin. Immunofluorescence microscopy showed the red phalloidin of stress fibers and lamellipodia in MDA-MB-231 cells (Fig. 6F). OE-FEN1 transfection increased the formation/maintenance of actin stress fibers, in contrast, KD-FEN1 transfection exhibited reduced stress fibers (Fig. 6F and G). These results indicated 

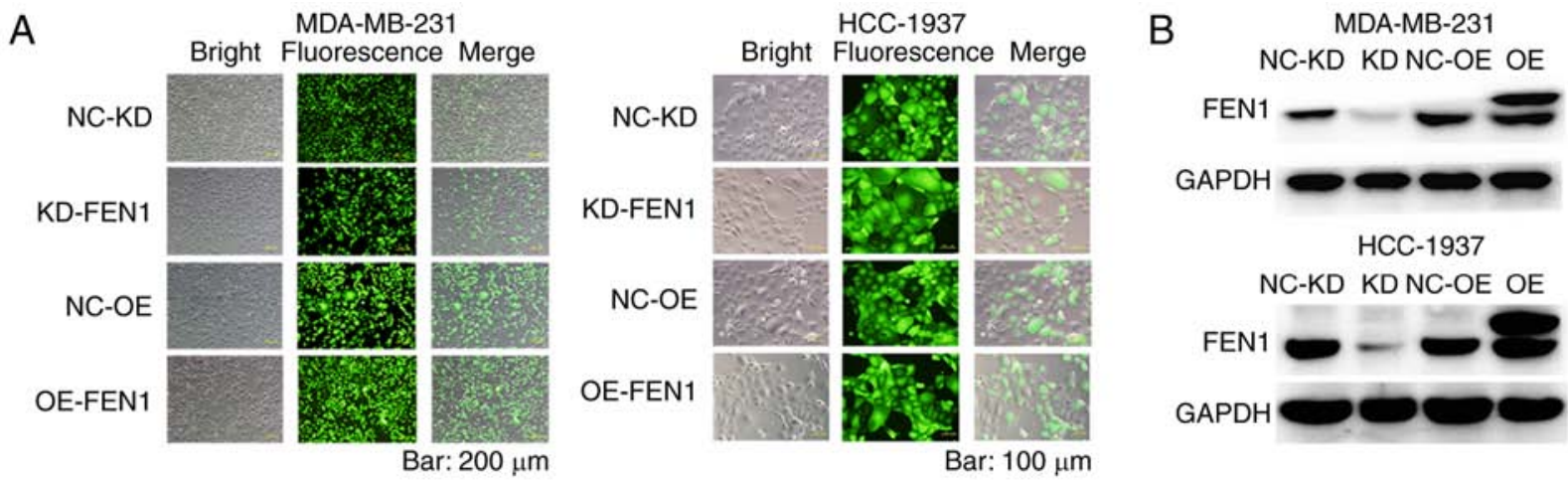

HCC-1937

NC-KD KD NC-OE OE
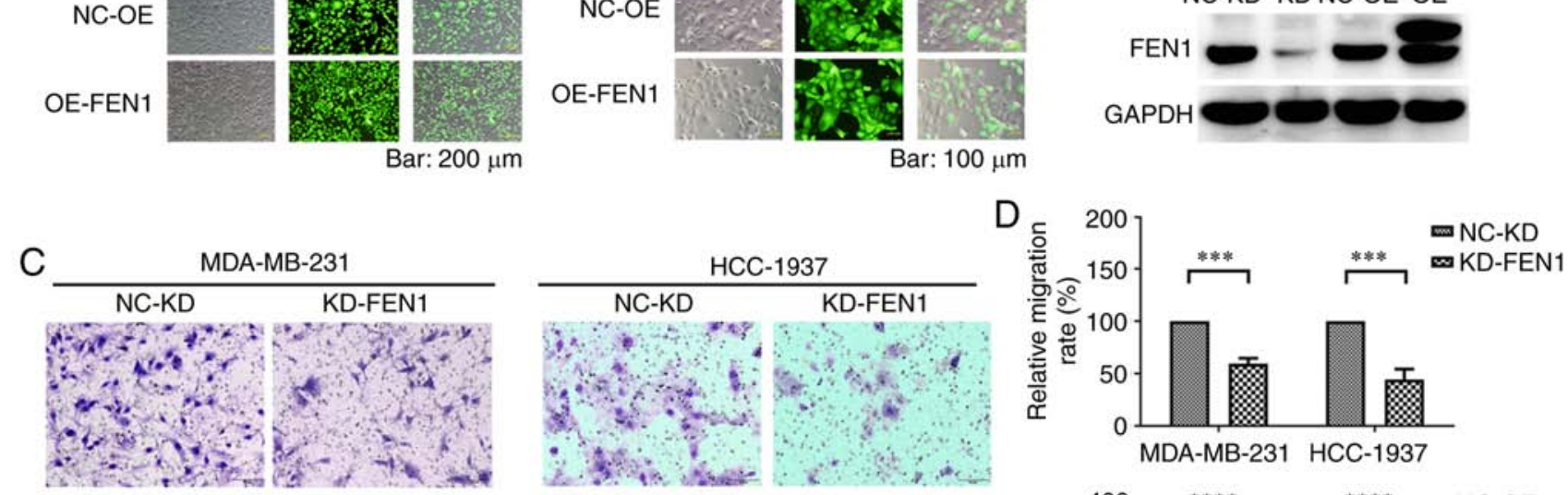

$$
\text { NC-OE OE-FEN1 }
$$
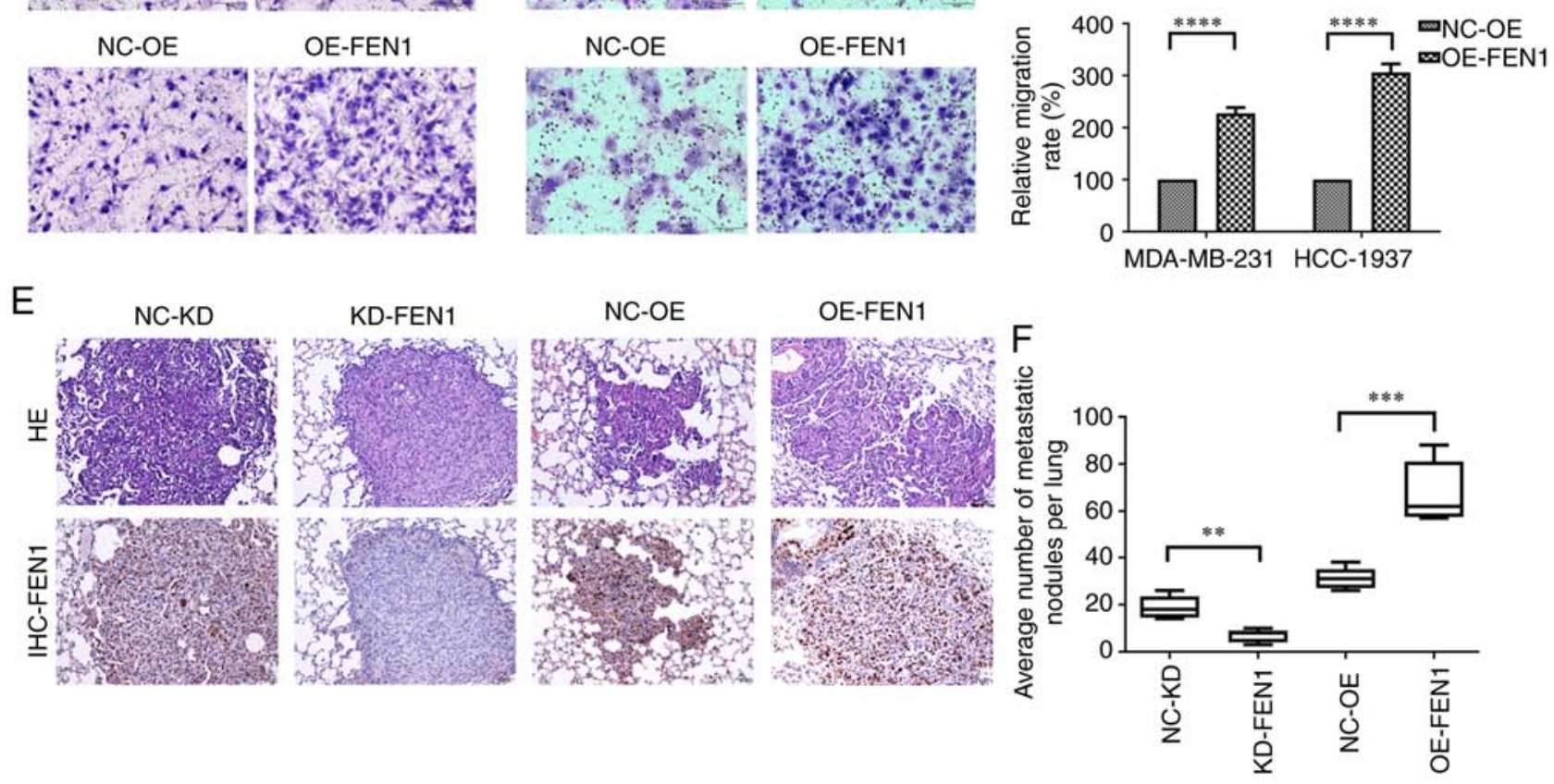

Figure 4. FEN1 expression in triple-negative breast cancer cell lines is associated with their migratory phenotype. The efficiency of FEN1 knockdown and overexpression was confirmed using (A) immunofluorescence (B) western blot analysis. (C and D) Migration assays were performed to investigate the effect of FEN1 knockdown and overexpression in the MDA-MB-231 and HCC1937 cell lines during cell migration. Data are presented as the mean \pm SD from three separate experiments. ${ }^{* * *} \mathrm{P}<0.001,{ }^{* * * *} \mathrm{P}<0.0001$ vs. control group. (E) A total of 8 weeks following tail-vein injection of cells with knockdown or overexpression of FEN1, or the control, the mice were euthanized and the lungs were isolated. Representative images of hematoxylin and eosin, and immunohistochemical staining of lung metastases in all the experimental groups. (F) Metastases in the lungs of mice $(n=5)$ were quantified. Mean nodule values per lung are shown. Data are presented as the mean $\pm \mathrm{SD} .{ }^{* *} \mathrm{P}<0.01,{ }^{* * *} \mathrm{P}<0.001$ vs. control group. Error bars are representative of triplicate experiments. FEN1, flap endonuclease-1.

that FEN1 facilitates TNBC cell migration by modulating the expression levels of PLK4 to enhance F-actin assembly, rather than activating EMT or matrix degradation.

\section{Discussion}

Despite advances in cancer treatment, the mortality rate of breast cancer is still high in women worldwide and metastasis remains the primary cause of cancer-related deaths. Compared with other subtypes of breast cancer, patients with TNBC are known to have the poorest prognosis and develop distant metastasis during the early stages, as the tumor cells possess a stronger ability of invasion and metastasis, which determines their higher malignancy (34). Therefore, an in-depth investigation into the mechanism of metastasis is crucial to improve the outcome in patients with TNBC. However, due to the complex mechanism of TNBC metastasis, some aspects remain unknown. FEN1 has been identified as a potential biomarker from previous studies, which found that overexpression of FEN1 could disrupt the cell cycle and promote cell proliferation in numerous types of cancer, including breast cancer $(13,24,35,36)$. Furthermore, FEN1 overexpression was 
A

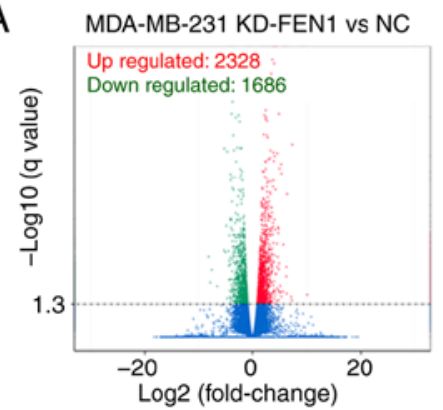

B

\section{HALLMARK_MITOTIC_SPINDLE \\ HALLMARK_DNA_REPAIR \\ HALLMARK_SPERMATOGENESIS \\ HALLMARK_E2F_TARGETS \\ HALLMARK_G2M_CHECKPOINT}

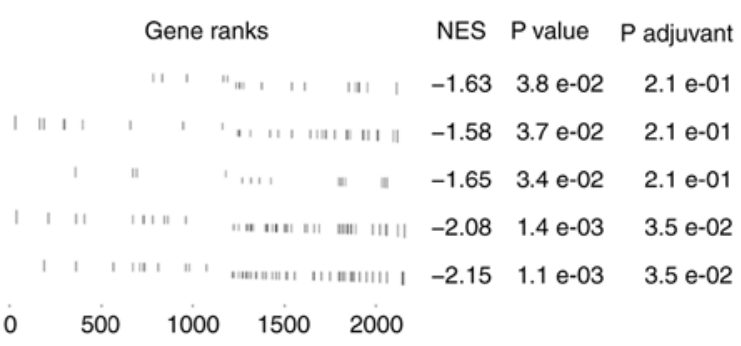

-Log (P-value)
C

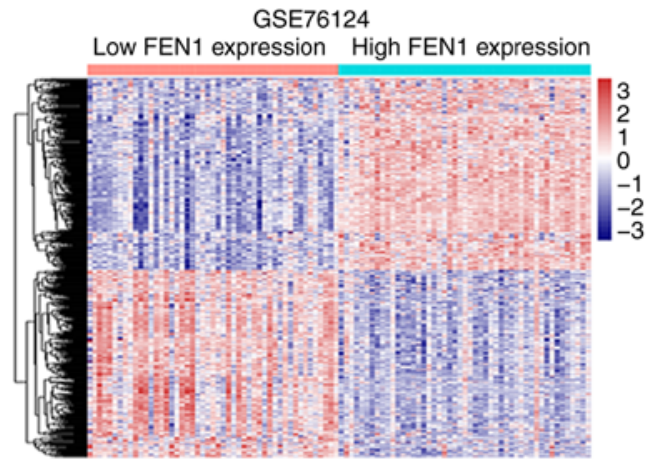

E

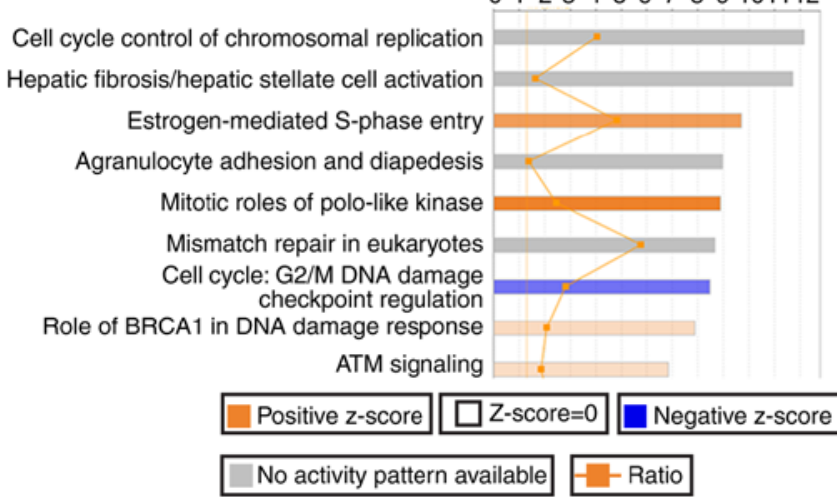

D

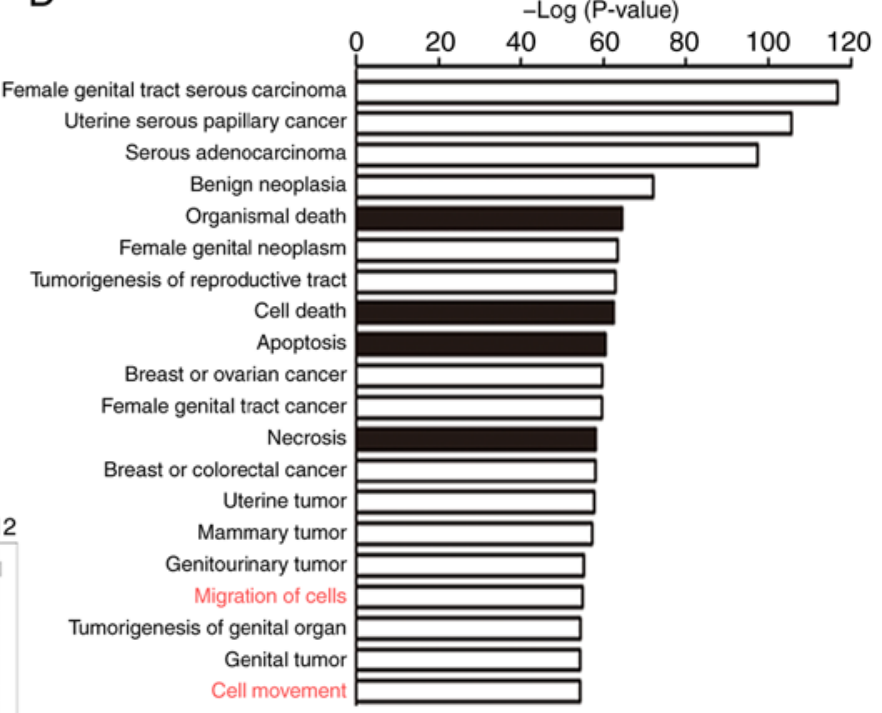

Figure 5. FEN1 promotes cell migration and mitosis in TNBC from the analysis of RNA-Sequencing data from (A and B) MDA-MB-231 cells and (C-E) 198 clinical TNBC tissues. (A) Volcano plot showing genes differentially expressed between FEN1 knockdown MDA-MB-231 cells and the negative control $\left[\mathrm{q}<0.01, \log _{2}\right.$ (fold change) $\left.>1\right]$. (B) Gene categories significantly enriched for genes deregulated in mitosis and $\mathrm{G}_{2} \mathrm{M}$ checkpoint revealed by MSigDB hallmark database analysis, following knockdown of FEN1 in the TNBC MDA-MB-231 cell line. Black bars denote the 245 significantly enriched sets. The uncategorized gene sets are not shown. The rows indicate the top 5 biological terms according to P-values. (C) Heatmap of the genes that were differentially expressed between patients with TNBC and high (top 25\%) and low expression levels of FEN1 (bottom 25\%) in the GSE76124 dataset ( $\mathrm{n}=198$ ). Fold change is indicated on the right. (D) The top 20 biological processes of FEN1-related transcripts in 198 patients with TNBC, as revealed by IPA and biofunctions analyses based on P-values, including two involved in cell migration and movement. Activated (white) and inhibited (black) FEN1-related biological functions are presented as-log (P-value) for the probability that the specific function is affected. (E) FEN1-related transcripts significantly enriched for pathways involved in the activation of polo-like kinase and the inhibition of $\mathrm{G}_{2} / \mathrm{M}$ checkpoint in 198 patients with TNBC, revealed by IPA pathway analysis. Overactivation (represented by positive z-score, orange) or suppression (represented by negative z-score, blue) are shown in the top eight canonical pathways, based on P-values. FEN1, flap endonuclease-1; TNBC, triple negative breast cancer.

also associated with resistance to chemotherapy $(18,22)$, and targeted therapy (37). In addition, some early studies showed that high FEN1 expression was associated with aggressive phenotypes in patients with breast, ovarian or prostate cancer $(9,38)$. The function of FEN1 has been characterized in several types of cancer, such as lung, colorectal, gastric, cervical, prostate and breast cancer $(9,11,13,14,18,19,21,23,35,38)$. However, the prognostic value of FEN1 in TNBC has not been elucidated. The present study provides support that FEN1 was associated with the triple-negative subtype of breast cancer, while overexpression of FEN1 was also associated with distant metastasis and unfavorable prognosis, which provides new perspectives and directions for investigating the metastatic mechanism of TNBC.

A recent study identified FENI as one of the hub upregulated-hypomethylated genes in breast cancer (39). Results of the COSMIC analysis revealed that the marked elevation of FEN1 expression was a common variant status in patients with breast cancer, indicating that FEN1 may be involved in tumorigenesis or tumor progression. Using the Oncomine database, increased FEN1 expression was associated with some aggressive breast tumor features, such as the ER-negative or TN subtypes, and advanced $\mathrm{N}$ and $\mathrm{M}$ stage. Patients with FEN1 mRNA overexpression had a significantly 
A
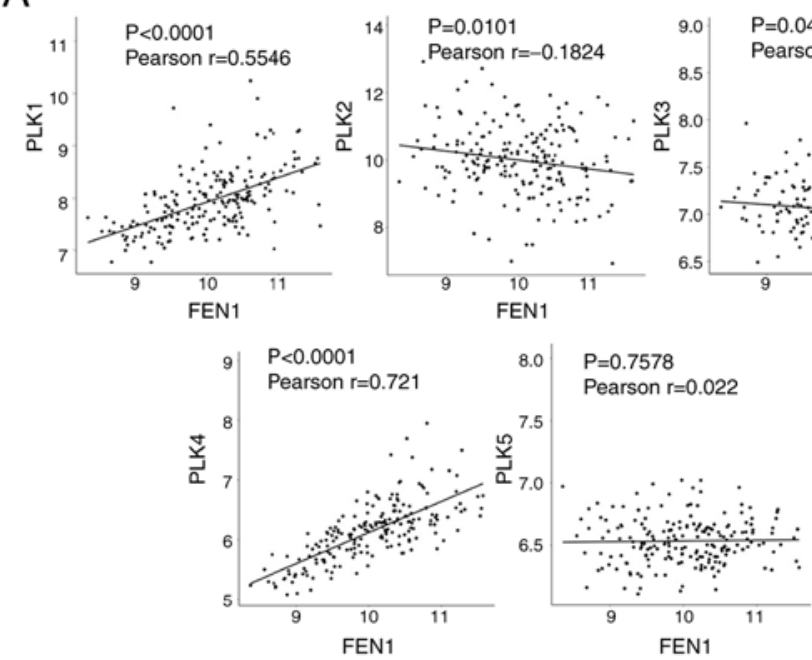

B

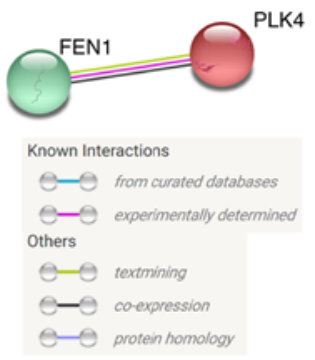

C

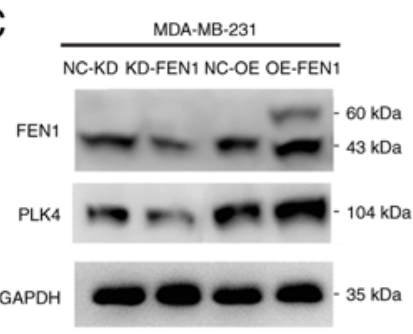

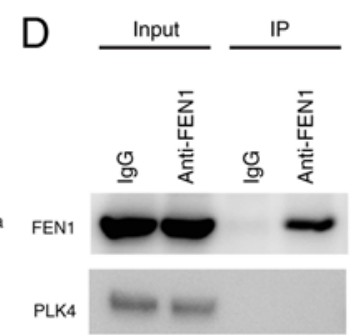

E MDA-MB-231

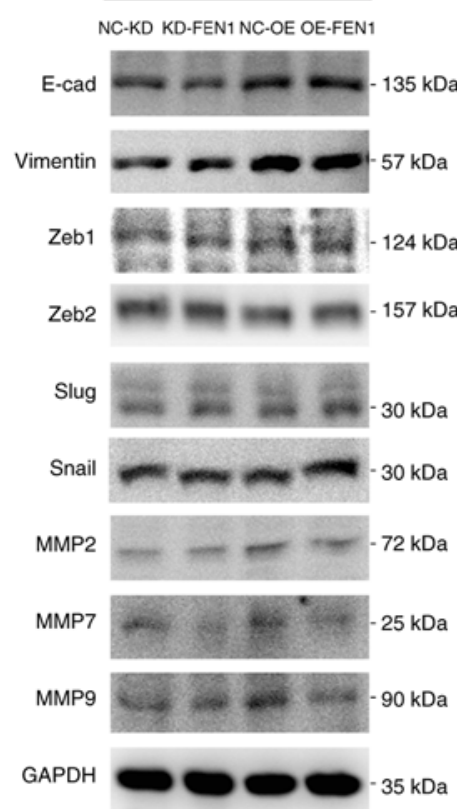

$\mathrm{F}$
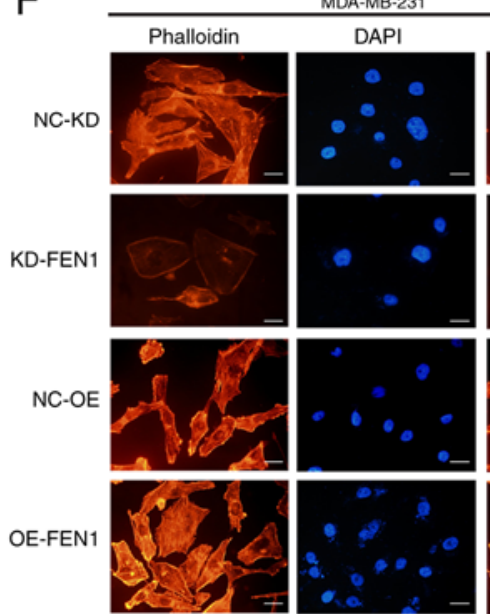
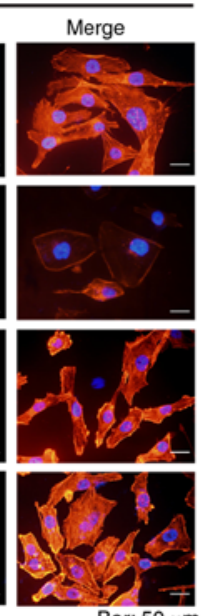

G
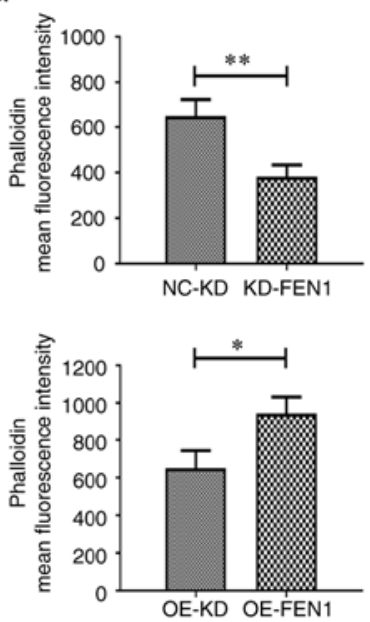

Figure 6. FEN1 promotes the migration and invasion of TNBC cells by modulating the expression level of PLK4. (A) Correlation analyses of FEN1 and members of the polo-like kinase family in 198 patients with TNBC, from the GSE76124 dataset. (B) PLK4 was directly associated with FEN1, as revealed by PPI network analysis (PPI enrichment P<0.001) using the Search Tool for the Retrieval of Interacting Genes/Proteins database. (C) Western blot analysis of PLK4 from the MDA-MB-231 cell line transfected with the FEN1 siRNA or FEN1 plasmid. (D) Western blot analysis of the indicated proteins from co-immunoprecipitation using anti-FEN1 or isotype control ( $\mathrm{IgG}$ ) antibodies in the MDA-MB-231 cell lines. (E) Western blot analysis of MMP or endothelial-mesenchymal transistion-associated proteins in the MDA-MB-231 cell line transfected with the shFEN1 plasmid or FEN1 plasmid. (F and G) Immunofluorescence analysis was performed to investigate the effect of FEN1 knockdown and overexpression on actin filament localization and the formation of specialized cell membrane structures in the MDA-MB-231 cell line. Actin filaments were stained with phalloidin linked to Texas Red (red staining), and the nuclei were counterstained with DAPI (blue staining). Scale bar, $50 \mu \mathrm{m}$. The data are presented as mean $\pm \mathrm{SD}$ of the membrane/cytosol actin fluorescent intensity ratio relative to the control. $\mathrm{n}=3 ;{ }^{*} \mathrm{P} \leq 0.05,{ }^{* *} \mathrm{P} \leq 0.01$. PPI, protein-protein interaction; si, short inhibiting; sh, short hairpin; TNBC, triple negative breast cancer.

higher rate of recurrence, metastasis and death. To verify the online analysis results, IHC analysis was performed using TMA-containing samples obtained from 248 patients with breast cancer who were recruited into the present study. The results revealed that patients with TNBC were more likely to have high expression levels of FEN1. Furthermore, patients with TNBC and high FEN1 expression levels were more likely to develop lymph node invasion and early distant metastasis, leading to poor overall survival, which was not observed in the total number of patients with breast cancer. To further determine the role of FEN1 in the invasion and metastasis of TNBC cells, two TNBC cell lines with FEN1 overexpression and knockdown were constructed to perform Transwell assay and to generate a TNBC lung metastasis model in nude mice. The results confirmed that FEN1 promoted metastasis both in vitro and in vivo.

To investigate the molecular mechanism by which FEN1 promotes TNBC cell metastasis, GSEA and IPA were used to analyze the transcription changes associated with FEN1 expression in MDA-MB-231 cells and in 198 patients with 
TNBC from the GSE76124 dataset. The results showed that FEN1 was positively associated with cell migration and cell movement biofunctions, which was consistent with the functional results. In addition, the biofunctions were involved in mitosis and cell cycle checkpoint regulation, which led to the further analysis of the polo-like kinase pathway, as it was found to significantly affect these biological processes (40), and was identified following IPA pathway analysis. Among the five members of the PLK protein family, Pearson's correlation analysis indicated that the expression level of FEN1 in patients with TNBC was highly correlated with the expression levels of PLK4. The analysis of the protein-protein interaction network, using the STRING database revealed that there may be co-expression between FEN1 and PLK4. However, the results from the immunoprecipitation experiments did not reveal any direct interaction. The western blot results revealed that knockdown of FEN1 attenuated the protein expression level of PLK4 in the MDA-MB-231 cell line, and vice versa. It has been demonstrated that PLK4 enhances cancer cell invasion (30-32) and its elevated expression was positively associated with lymph node metastasis and distant metastasis in patients with breast cancer (41). With respect to the previous studies, we hypothesized that FEN1 may promote the migration and invasion of TNBC cells by modulating the expression level of PLK4. Previous findings have shown that PLK4 promoted tumor invasion by mediating EMT $(30,31)$. However, after examining the expression levels of the EMT-associated proteins and MMPs in the MDA-MB-231 cell line, there were no changes following FEN1 knockdown or overexpression. Except for the EMT process, PLK4 promotes cancer cell motility and actin dynamics through interaction with the Arp2/3 complex and the @GTPase pathways (42). Therefore, whether FEN1 would be required for actin rearrangement, using immunofluorescence was investigated and the results revealed that the density of F-actin in FEN1 knockdown TNBC cells was significantly decreased, while the density was significantly increased following FEN1 overexpression. In summary, the present study found that FEN1 facilitates TNBC cell migration by enhancing F-actin assembly, rather than activating EMT or matrix degradation.

However, there are limitations to the present study. Firstly, TNBC is a general term for a heterogeneous type of breast cancer, which can be divided into six subtypes (43). The current study was limited by the small sample size and due to the lack of previous studies investigating the association between FEN1 and the TN subtype, which is to be part of future research. Secondly, more biological experiments are required to explore the complex relationship between FEN1 and PLK4.

In summary, the present study revealed that FEN1 was associated with TNBC invasion and metastasis, and could modulate PLK4 expression and actin cytoskeleton rearrangement. The results suggested that FEN1 could be potentially utilized as a novel biomarker for TNBC prognosis and a therapeutic target for patients with TNBC.

\section{Acknowledgements}

Not applicable.

\section{Funding}

This study was supported by the National Natural Science Foundation of China (NSFC, no. 81672605), National Science and Technology Major Project of the Ministry of Science and Technology of China (no. 2017ZX09304025), and National Key R\&D Program of China (no. 2018YFC1311600).

\section{Availability of data and materials}

The datasets used and analyzed during the current study are available from the corresponding author on reasonable request.

\section{Authors' contributions}

LX was involved in the conception, design and coordination of the study as well as in data analysis, interpretation of results and drafting the manuscript. JLQ, NS, XZ, XFC, KZH, SS, ZYF and XJQ participated in the experimental procedures and revised critically the content of the manuscript. LYZ, YET and YPL conceived, designed the experiments and critically revised the manuscript. All authors read and approved the final manuscript.

\section{Ethics approval and consent to participate}

Ethics approval was obtained from the Ethics Committee of the First Hospital of China Medical University, and written informed consent was obtained from each patient. Animal experiments were approved by the China Medical University Application for Laboratory Animal Welfare and Ethical review.

\section{Patient consent for publication}

Not applicable.

\section{Competing interests}

The authors declare that there is no conflict of interests.

\section{References}

1. Bianchini G, Balko JM, Mayer IA, Sanders ME and Gianni L: Triple-negative breast cancer: Challenges and opportunities of a heterogeneous disease. Nat Rev Clin Oncol 13: 674-690, 2016.

2. Dent R, Trudeau M, Pritchard KI, Hanna WM, Kahn HK, Sawka CA, Lickley LA, Rawlinson E, Sun P and Narod SA: Triple-negative breast cancer: Clinical features and patterns of recurrence. Clin Cancer Res 13: 4429-4434, 2007.

3. Tischkowitz M, Brunet JS, Bégin LR, Huntsman DG, Cheang MC Akslen LA, Nielsen TO and Foulkes WD: Use of immunohistochemical markers can refine prognosis in triple negative breast cancer. BMC Cancer 7: 134, 2007.

4. Bakhoum SF, Ngo B, Laughney AM, Cavallo JA, Murphy CJ, Ly P, Shah P, Sriram RK, Watkins TBK, Taunk NK, et al: Chromosomal instability drives metastasis through a cytosolic DNA response. Nature 553: 467-472, 2018.

5. Jing A, Vizeacoumar FS, Parameswaran S, Haave B, Cunningham CE, Wu Y, Arnold R, Bonham K, Freywald A, Han J and Vizeacoumar FJ: Expression-based analyses indicate a central role for hypoxia in driving tumor plasticity through microenvironment remodeling and chromosomal instability. NPJ Syst Biol Appl 4: 38, 2018. 
6. Robinson DR, Wu YM, Lonigro RJ, Vats P, Cobain E, Everett J, Cao X, Rabban E, Kumar-Sinha C, Raymond V, et al: Integrative clinical genomics of metastatic cancer. Nature 548: 297-303, 2017.

7. Pilie PG, Tang C, Mills GB and Yap TA: State-of-the-art strategies for targeting the DNA damage response in cancer. Nat Rev Clin Oncol 16: 81-104, 2019.

8. Balakrishnan L and Bambara RA: Flap endonuclease 1. Annu Rev Biochem 82: 119-138, 2013.

9. Abdel-Fatah TM, Russell R, Albarakati N, Maloney DJ, Dorjsuren D, Rueda OM, Moseley P, Mohan V, Sun H, Abbotts R, et al: Genomic and protein expression analysis reveals flap endonuclease 1 (FEN1) as a key biomarker in breast and ovarian cancer. Mol Oncol 8: 1326-1338, 2014.

10. Ali R, Rakha EA, Madhusudan S and Bryant HE: DNA damage repair in breast cancer and its therapeutic implications. Pathology 49: 156-165, 2017.

11. He L, Luo L, Zhu H, Yang H, Zhang Y, Wu H, Sun H, Jiang F, Kathera CS, Liu L, et al: FEN1 promotes tumor progression and confers cisplatin resistance in non-small-cell lung cancer. Mol Oncol 11: 640-654, 2017.

12. He L, Yang H, Zhou S, Zhu H, Mao H, Ma Z, Wu T, Kumar AK, Kathera C, Janardhan A, et al: Synergistic antitumor effect of combined paclitaxel with FEN1 inhibitor in cervical cancer cells. DNA Repair (Amst) 63: 1-9, 2018.

13. He L, Zhang Y, Sun H, Jiang F, Yang H, Wu H, Zhou T, Hu S, Kathera CS, Wang X, et al: Targeting DNA flap endonuclease 1 to impede breast cancer progression. EBioMedicine 14: 32-43, 2016.

14. Hwang JC, Sung WW, Tu HP, Hsieh KC, Yeh CM, Chen CJ, Tai HC, Hsu CT, Shieh GS, Chang JG, et al: The overexpression of FEN1 and RAD54B May Act as independent prognostic factors of lung adenocarcinoma. PLoS One 10: e0139435, 2015

15. Isohookana J, Haapasaari KM, Soini Y, Leppanen J and Karihtala P: Proteins of the retinoblastoma pathway, FEN1 and MGMT are novel potential prognostic biomarkers in pancreatic adenocarcinoma. Pathol Res Pract 214: 840-847, 2018

16. Kim JM, Sohn HY, Yoon SY, Oh JH, Yang JO, Kim JH, Song KS Rho SM, Yoo HS, Kim YS, et al: Identification of gastric cancer-related genes using a cDNA microarray containing novel expressed sequence tags expressed in gastric cancer cells. Clin Cancer Res 11: 473-482, 2005.

17. Narayan S and Sharma R: Molecular mechanism of adenomatous polyposis coli-induced blockade of base excision repair pathway in colorectal carcinogenesis. Life Sci 139: 145-152, 2015.

18. Nikolova T, Christmann M and Kaina B: FEN1 is overexpressed in testis, lung and brain tumors. Anticancer Res 29: 2453-2459, 2009.

19. Sato M, Girard L, Sekine I, Sunaga N, Ramirez RD, Kamibayashi C and Minna JD: Increased expression and no mutation of the Flap endonuclease (FEN1) gene in human lung cancer. Oncogene 22: 7243-7246, 2003.

20. Singh P, Yang M, Dai H, Yu D, Huang Q, Tan W, Kernstine KH, Lin D and Shen B: Overexpression and hypomethylation of flap endonuclease 1 gene in breast and other cancers. Mol Cancer Res 6: 1710-1717, 2008.

21. Wang J, Zhou L, Li Z, Zhang T, Liu W, Liu Z, Yuan YC, Su F, Xu L, Wang Y, et al: YY1 suppresses FEN1 over-expression and drug resistance in breast cancer. BMC Cancer 15: 50, 2015

22. Xie C, Wang $\mathrm{K}$ and Chen D: Flap endonuclease 1 silencing is associated with increasing the cisplatin sensitivity of SGC7901 gastric cancer cells. Mol Med Rep 13: 386-392, 2016.

23. Zhang K, Keymeulen S, Nelson R, Tong TR, Yuan YC, Yun X, Liu Z, Lopez J, Raz DJ and Kim JY: Overexpression of flap endonuclease 1 correlates with enhanced proliferation and poor prognosis of non-small-cell lung cancer. Am J Pathol 188: 242-251, 2018

24. Zeng X, Qu X, Zhao C, Xu L, Hou K, Liu Y, Zhang N, Feng J, Shi S, Zhang L, et al: FEN1 mediates miR-200a methylation and promotes breast cancer cell growth via MET and EGFR signaling. FASEB J 33: 10717-10730, 2019.

25. Forbes SA, Beare D, Boutselakis H, Bamford S, Bindal N, Tate J, Cole CG, Ward S, Dawson E, Ponting L, et al: COSMIC: Somatic cancer genetics at high-resolution. Nucleic Acids Res 45 D777-D783, 2017.
26. Rhodes DR, Kalyana-Sundaram S, Mahavisno V, Varambally R, Yu J, Briggs BB, Barrette TR, Anstet MJ, Kincead-Beal C, Kulkarni P, et al: Oncomine 3.0: Genes, pathways, and networks in a collection of 18,000 cancer gene expression profiles Neoplasia 9: 166-180, 2007.

27. Liu W, Zhang L, Shi J, Liu Y, Zhou L, Hou K, Qu X and Teng Y: Clinical significance of pAkt and pErk1/2 expression in early-stage breast cancer patients treated with anthracycline-based adjuvant chemotherapy. Oncol Lett 9: 1707-1714, 2015.

28. Kramer A, Green J, Pollard J Jrand Tugendreich S: Causal analysis approaches in Ingenuity pathway analysis. Bioinformatics 30: 523-530, 2014

29. Li H, Xu L, Li C, Zhao L, Ma Y, Zheng H, Li Z, Zhang Y, Wang R, Liu Y and Qu X: Ubiquitin ligase Cbl-b represses IGF-I-induced epithelial mesenchymal transition via ZEB2 and microRNA-200c regulation in gastric cancer cells. Mol Cancer 13: 136, 2014.

30. Tian X, Zhou D, Chen L, Tian Y, Zhong B, Cao Y, Dong Q, Zhou M, Yan J, Wang Y, et al: Polo-like kinase 4 mediates epithelial-mesenchymal transition in neuroblastoma via PI3K/Akt signaling pathway. Cell Death Dis 9: 54, 2018.

31. Liao Z, Zhang H, Fan P, Huang Q, Dong K, Qi Y, Song J, Chen L, Liang H, Chen X, et al: High PLK4 expression promotes tumor progression and induces epithelial-mesenchymal transition by regulating the $\mathrm{Wnt} / \beta$-catenin signaling pathway in colorectal cancer. Int J Oncol 54: 479-490, 2019.

32. Kazazian K, Go C, Wu H, Brashavitskaya O, Xu R, Dennis JW, Gingras AC and Swallow CJ: Plk4 promotes cancer invasion and metastasis through Arp2/3 complex regulation of the actin cytoskeleton. Cancer Res 77: 434-447, 2017.

33. Rosario CO, Kazazian K, Zih FS, Brashavitskaya O, Haffani Y, Xu RS, George A, Dennis JW and Swallow CJ: A novel role for Plk4 in regulating cell spreading and motility. Oncogene 34: 3441-3451, 2015.

34. Foulkes WD, Smith IE and Reis-Filho JS: Triple-negative breast cancer. N Engl J Med 363: 1938-1948, 2010.

35. Wang $\mathrm{K}, \mathrm{Xie} \mathrm{C}$ and Chen D: Flap endonuclease 1 is a promising candidate biomarker in gastric cancer and is involved in cell proliferation and apoptosis. Int J Mol Med 33: 1268-1274, 2014.

36. Sang Y, Bo L, Gu H, Yang W and Chen Y: Flap endonuclease-1 rs174538 G>A polymorphisms are associated with the risk of esophageal cancer in a Chinese population. Thorac Cancer 8: 192-196, 2017.

37. Zeng X, Che X, Liu YP, Qu XJ, Xu L, Zhao CY, Zheng CL, Hou KZ and Teng Y: FEN1 knockdown improves trastuzumab sensitivity in human epidermal growth factor 2-positive breast cancer cells. Exp Ther Med 14: 3265-3272, 2017.

38. Lam JS, Seligson DB, Yu H, Li A, Eeva M, Pantuck AJ, Zeng G, Horvath S and Belldegrun AS: Flap endonuclease 1 is overexpressed in prostate cancer and is associated with a high gleason score. BJU Int 98: 445-451, 2006.

39. Qi L, Zhou B, Chen J, Hu W, Bai R, Ye C, Weng X and Zheng S: Significant prognostic values of differentially expressed-aberrantly methylated hub genes in breast cancer. J Cancer 10: 6618-6634, 2019

40. Zitouni S, Nabais C, Jana SC, Guerrero A and Bettencourt-Dias M: Polo-like kinases: Structural variations lead to multiple functions. Nat Rev Mol Cell Biol 15: 433-452, 2014.

41. Li Z, Dai K, Wang C, Song Y, Gu F, Liu F and Fu L: Expression of polo-like kinase 4(PLK4) in breast cancer and its response to taxane-based neoadjuvant chemotherapy. J Cancer 7: 1125-1132, 2016.

42. Ling H, Hanashiro K, Luong TH, Benavides L and Fukasawa K: Functional relationship among PLK2, PLK4 and ROCK2 to induce centrosome amplification. Cell Cycle 14: 544-553, 2015.

43. Lehmann BD, Bauer JA, Chen X, Sanders ME, Chakravarthy AB, Shyr Y and Pietenpol JA: Identification of human triple-negative breast cancer subtypes and preclinical models for selection of targeted therapies. J Clin Invest 121: 2750-2767, 2011.

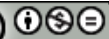

This work is licensed under a Creative Commons Attribution-NonCommercial-NoDerivatives 4.0 International (CC BY-NC-ND 4.0) License. 